\title{
A retrospective analysis of 20-year data of the surgical management of ulcerative colitis patients in Taiwan: a study of Taiwan Society of Inflammatory Bowel Disease
}

\author{
Chun-Chi Lin ${ }^{1}$, Shu-Chen Wei ${ }^{2}$, Been-Ren Lin ${ }^{3}$, Wen-Sy-Tsai ${ }^{4}$, Jinn-Shiun Chen ${ }^{4}$, Tzu-Chi Hsu ${ }^{5}$, \\ Wei-Chen Lin ${ }^{6}$, Tien-Yu Huang ${ }^{7}$, Te-Hsin Chao ${ }^{8}$, Hung-Hsin Lin ${ }^{1}$, Jau-Min Wong ${ }^{2}$, Jen-Kou Lin ${ }^{1}$ \\ ${ }^{1}$ Division of Colon and Rectal Surgery, Department of Surgery, Taipei Veterans General Hospital and Department of Surgery, National Yang- \\ Ming University, Taipei, ${ }^{2}$ Department of Internal Medicine, National Taiwan University Hospital, Taipei, ${ }^{3}$ Division of Colon and Rectal Surgery, \\ Department of Surgery, National Taiwan University Hospital, Taipei, ${ }^{4}$ Division of Colorectal Surgery, Chang Gung Memorial Hospital at \\ Linkou, Taoyuan, ${ }^{5}$ Division of Colon and Rectal Surgery, Department of Surgery, Mackay Memorial Hospital, Taipei, ${ }^{6}$ Department of Internal \\ Medicine, Mackay Memorial Hospital, Taipei, ${ }^{7}$ Division of Gastroenterology, Department of Internal Medicine, Tri-Service General Hospital, \\ National Defense Medical Center, Taipei, ${ }^{8}$ Division of Colorectal Surgery, Department of Surgery, Taichung Veterans General Hospital, \\ Taichung, Taiwan
}

Background/Aims: With the recent progress in medical treatment, surgery still plays a necessary and important role in treating ulcerative colitis (UC) patients. In this study, we analyzed the surgical results and outcomes of UC in Taiwan in the recent 20 years, via a multi-center study through the collaboration of Taiwan Society of IBD. Methods: A retrospective analysis of surgery data of UC patients from January 1, 1995, through December 31, 2014, in 6 Taiwan major medical centers was conducted. The patients' demographic data, indications for surgery, and outcome details were recorded and analyzed. Results: The data of 87 UC patients who received surgical treatment were recorded. The median post-operative follow-up duration was 51.1 months and ranged from 0.4 to 300 months. The mean age at UC diagnosis was $45.3 \pm 16.0$ years and that at operation was $48.5 \pm 15.2$ years. The 3 leading indications for surgical intervention were uncontrolled bleeding (16.1\%), perforation ( $13.8 \%)$, and intractability (12.6\%). In total, $27.6 \%$ of surgeries were performed in an emergency setting. Total or subtotal colectomy with rectal preservation $(41.4 \%)$ was the most common operation. There were 6 mortalities, all due to sepsis. Emergency operation and low pre-operative albumin level were significantly associated with poor survival $(P=0.013$ and 0.034 , respectively). Conclusions: In the past 20 years, there was no significant change in the indications for surgery in UC patients. Emergency surgeries and low pre-operative albumin level were associated with poor survival. Therefore, an optimal timing of elective surgery for people with poorly controlled UC is paramount. (Intest Res 2016;14:248-257)

Key Words: Colitis, ulcerative; Surgery; Prognosis

\section{INTRODUCTION}

Ulcerative Colitis (UC) was first described by the British

Received March 21, 2016. Revised April 25, 2016

Accepted May 9, 2016

Correspondence to Jen-Kou Lin, Department of Surgery, Taipei Veterans General Hospital, No. 201, Sec. 2, Shipai Rd., Beitou District, Taipei City,

Taiwan 11217, ROC. Tel: +886-2-28757100, Fax: +886-2-2875-7534,

E-mail:jklin@vghtpe.gov.tw

Financial support: None. Conflict of interest: None. physician Sir Samuel Wilks in 1859. ${ }^{1}$ It is an IBD that causes diffuse inflammatory mucosal injury, including erosions and ulcers in the colon and rectum. ${ }^{2,3}$ Patients present with symptoms such as diarrhea, the passage of mucobloody stools, tenesmus, and abdominal pain unless appropriate treatment is provided. The goal of treatment is to achieve and sustain clinical remission, as confirmed by the disappearance of clinical symptoms, and endoscopic mucosal healing. Most physicians use the step-up approach while

\footnotetext{
(c) Copyright 2016. Korean Association for the Study of Intestinal Diseases. All rights reserved.

This is an Open Access article distributed under the terms of the Creative Commons Attribution Non-Commercial License (http://creativecommons.org/licenses/by-nc/4.0)

which permits unrestricted non-commercial use, distribution, and reproduction in any medium, provided the original work is properly cited.
} 
treating UC patients. In patients with mild-to-moderate UC, the first line of treatment is a 5-aminosalicylic acid (5-ASA)related medication, which is considered to be an effective treatment that provides rapid symptom relief. ${ }^{4,5}$ In the case of insufficient response or intolerance to 5-ASA, patients may require corticosteroids and/or immunomodulators (IMMs) such as azathioprine or 6-mercaptopurine as a step-up therapy. ${ }^{6,7}$ Furthermore, for moderate-to-severe UC patients, calcineurin inhibitors or anti-tumor necrosis factor (TNF) agents might be helpful. ${ }^{8,9}$ In cases in which medical therapies fail or there are acute abdominal symptoms, surgical intervention plays a role in salvaging patients and curing UC.

Although most UC patients can be treated effectively by a wide variety of medications, most methods are not curative. However, the removal of the colon and rectum is curative and eliminates the possibility of malignancy, wherein the most important risk factors are the duration and extent of disease. ${ }^{10}$ In addition, surgery can eliminate the need for patients to take long-term anti-inflammatory medications or IMMs.

It has been reported that approximately $15 \%-45 \%$ of UC patients require surgery in their lifetime, and the colectomy rates for UC vary geographically. ${ }^{11}$ The colectomy rate is generally lower in Asians with UC than in patients from Western countries, and ranges from $3 \%-16 \%{ }^{12-17}$ Surgical indications vary from acute colitis to malignancy and often have a dramatic impact on morbidity, mortality, and quality of life, especially in conditions where surgery is a rescue therapy or in an emergency setting. ${ }^{18,19}$

Several reports have discussed the surgical outcomes of patients with UC, either in the context of single center ${ }^{20-24}$ or population-based studies. ${ }^{25,26}$ The reported mortality rate in the post-operative period ranged from $0-4.7 \%$. In Asia, some studies have also investigated the surgical outcomes of UC patients. ${ }^{1724}$ However, to the best of our knowledge, no multicenter studies on the outcomes of colectomy in UC patients have been published, especially in low-endemic areas such as Taiwan.

In this study, we aimed to analyze the surgical results and outcomes of UC patients in Taiwan in the past 20 years via a multi-center study in collaboration with the Taiwan Society of IBD.

\section{METHODS}

\section{Patients}

In collaboration with the Taiwan Society of IBD, we conducted a retrospective analysis of the surgical data of UC patients in six medical centers in Taiwan from January 1 , 1995 to December 31, 2014. The medical centers included Linkou Chang Gung Memorial Hospital, Mackay Memorial Hospital, National Taiwan University Hospital, Taichung Veterans General Hospital, Taipei Veterans General Hospital, and Tri-Service General Hospital. Diagnosis of UC was based on clinical, radiological, and histological features. ${ }^{7,27}$ The collected data included sex, age at diagnosis, the extent of UC, surgery dates and times, the medications used before and after surgery, indications for surgery, surgical methods and disease status after surgery, last follow up, and survival condition. For further analysis of chronological changes, we divided the study period into quarters, with 5 years for each period. In addition, laboratory data before surgery, such as albumin levels, hemoglobin levels, white blood cell counts, platelet levels, and CRP levels, were also collected for analysis.

\section{Definitions of Disease Extent, Emergency/Elective Surgery, and Remission}

The extent of UC was categorized into three groups: $:^{28}$ proctitis involvement limited to the rectum, left-sided colitis limited to the proportion of the colon distal to the splenic flexure, and extensive colitis extending proximally to the splenic flexure, including pancolitis. Medications before and after surgery included 5-ASA or sulfasalazine, systemic steroids, IMMs (azathioprine, 6-mercaptopurine, or methotrexate), calcineurin inhibitors (cyclosporine or tacrolimus), and anti-TNF- $\alpha$ agents.

An emergency indication was defined as a medical emergency for which immediate surgical intervention was the only way to solve the life-threatening problems successfully, while elective surgery was defined as surgery scheduled in advance because it did not involve a medical emergency. An emergency operation may be indicated in cases of toxic megacolon, ${ }^{29}$ perforation, hemorrhage, and toxic colitis ${ }^{30}$ unresponsive to medical therapy.

Remission was defined as a complete resolution of symptoms (bowel movement frequency $<3$ per day without bleeding or urgency). ${ }^{31}$ Otherwise, patients were considered to have active disease. The last follow-up date was the latest patient visit or the date of patient death. 


\section{Statistical Analysis}

Continuous data variables were expressed as means \pm SD and categorical data as percentages. Student's $t$-test was used to assess continuous variables and the chi-square test was used for the assessment of categorical variables. If the cells had an expected count of $<5$, then Fisher's exact test was applied. Normally distributed and asymmetric variables were compared using the Mann-Whitney $U$ test. Receiver operating characteristics analysis was used for the selection of cut-off values of serodiagnostic tests. Survival analysis was performed using the Kaplan-Meier method and log-rank test. All statistical analyses were conducted using SPSS software version 16.0 (SPSS Inc., Chicago, IL, USA).

\section{RESULTS}

\section{Demographic Characteristics}

A total of 87 UC patients who underwent surgery in the six medical centers between January 1, 1995 and December 31, 2014 were enrolled in this study. The median post-operative follow up duration was 51.1 months and ranged from 0.4300 months. The mean age at UC diagnosis was $45.3 \pm 16.0$ years and the mean age at the time of surgery was $48.5 \pm 15.2$ years (Table 1). An overall male predominance $(62.1 \%)$ was noted in the cohort. Extensive colitis was the most common phenotype (77.0\%). Among the surgical cohort, $64.4 \%$ patients were receiving 5-ASA or sulfasalazine and $40.2 \%$ were receiving systemic steroids before surgery. Most of the surgeries were performed in the past 10 years and most patients (67.8\%) achieved remission after surgery. There were six mortalities in the study period.

The three leading indications (Table 2) for surgical intervention were uncontrolled bleeding ( $16.1 \%)$, perforation (13.8\%), and intractability (12.6\%). More than $50 \%$ of patients underwent surgery in an elective setting (55.2\%). The most common surgical method was total or subtotal colectomy with rectal preservation (41.4\%), followed by total abdominal proctocolectomy with ileal pouch-anal anastomosis (IPAA) (25.3\%), and segmental colectomy (17.2\%). One patient received total proctocolectomy with IPAA due to persistent moderate active colitis after segmental colectomy and end colostomy. Only nine patients (10.3\%) received laparoscopic surgery. Among the 87 patients, 60 patients $(69.0 \%)$ received diversion in the index operation and 42 patients (48.8\%) were left with a permanent stoma (Table 2).
Table 1. Characteristics of the UC Population

\begin{tabular}{|c|c|}
\hline Item & Patients $(n=87)$ \\
\hline Age & $45.3 \pm 16.0$ \\
\hline BMI & $21.0 \pm 3.8$ \\
\hline \multicolumn{2}{|l|}{ Sex } \\
\hline Male & $54(62.1)$ \\
\hline Female & $33(37.9)$ \\
\hline \multicolumn{2}{|l|}{ Extent at diagnosis } \\
\hline Proctitis & $3(3.4)$ \\
\hline Left-side colitis & $15(17.2)$ \\
\hline Extensive colitis & 67 (77.0) \\
\hline NA & $2(2.3)$ \\
\hline \multicolumn{2}{|c|}{ Medications before operation } \\
\hline 5-ASA or sulfasalazine & $56(64.4)$ \\
\hline Systemic steroid & $35(40.2)$ \\
\hline ammunomodulators & $3(3.4)$ \\
\hline${ }^{b}$ Calcineurin inhibitors & $3(3.4)$ \\
\hline TNF antagonists & $1(1.1)$ \\
\hline No medication & $16(18.4)$ \\
\hline NA & $13(14.9)$ \\
\hline \multicolumn{2}{|c|}{ Medications after operation } \\
\hline 5-ASA or sulfasalazine & $31(35.6)$ \\
\hline Systemic steroid & $11(12.6)$ \\
\hline ammunomodulators & $3(3.4)$ \\
\hline${ }^{b}$ Calcineurin inhibitors & 0 \\
\hline TNF antagonists & 0 \\
\hline No medication & $34(39.1)$ \\
\hline NA & $15(17.2)$ \\
\hline \multicolumn{2}{|l|}{ Operation year } \\
\hline 1994-1999 & $3(3.4)$ \\
\hline 1999-2004 & $5(8.2)$ \\
\hline 2004-2009 & $32(36.8)$ \\
\hline 2009-2014 & 35 (40.2) \\
\hline NA & 12 (13.8) \\
\hline \multicolumn{2}{|c|}{ Disease status after operation } \\
\hline Active & 8 (9.2) \\
\hline Remission & $59(67.8)$ \\
\hline $\mathrm{NA}$ & $20(23.0)$ \\
\hline \multicolumn{2}{|l|}{ Disease to operation } \\
\hline$\leq 1 \mathrm{yr}$ & 38 (43.7) \\
\hline $1-5$ yrs & 12 (13.8) \\
\hline $6-10$ yrs & 11 (12.6) \\
\hline$\geq 10$ yrs & 13 (14.9) \\
\hline NA & 13 (14.9) \\
\hline \multicolumn{2}{|l|}{ Survival } \\
\hline Yes & 68 (78.2) \\
\hline No & $6(6.9)$ \\
\hline NA & $13(14.9)$ \\
\hline
\end{tabular}

Values are presented as mean \pm SD or $n(\%)$.

Immunomodulators: azathioprine, 6-mercaptopurine, or methotrexate.

${ }^{b}$ Calcineurin inhibitors: cyclosporine or tacrolimus.

NA, not available; 5-ASA, 5-aminosalicylic acid; TNF, tumor necrosis factor. 
Table 2. Operative Details of UC Patients

\begin{tabular}{|c|c|}
\hline Item & $\begin{array}{c}\text { Patients } \\
(n=87)\end{array}$ \\
\hline \multicolumn{2}{|l|}{ Indication for operation } \\
\hline Toxic megacolon & $5(5.7)$ \\
\hline Toxic colitis & $8(9.2)$ \\
\hline Perforation & $12(13.8)$ \\
\hline Uncontrolled bleeding & $14(16.1)$ \\
\hline Intractability & $11(12.6)$ \\
\hline Stenosis & $4(4.6)$ \\
\hline Dysplasia or adenocarcinoma & $9(10.3)$ \\
\hline Adhesion ileus & $3(3.4)$ \\
\hline NA & $21(24.1)$ \\
\hline \multicolumn{2}{|l|}{ Emergency or elective } \\
\hline Emergency & $24(27.6)$ \\
\hline Elective & $48(55.2)$ \\
\hline NA & $15(17.2)$ \\
\hline \multicolumn{2}{|l|}{ Operation method } \\
\hline Proctocolectomy with ileostomy & $4(4.6)$ \\
\hline Total or subtotal colectomy with rectal preservation & $34(41.4)$ \\
\hline Total abdominal proctocolectomy with IPAA & $22(25.3)$ \\
\hline Segmental colectomy & $15(17.2)$ \\
\hline Hartmann procedure & $3(3.4)$ \\
\hline Diverting loop ileostomy & $6(6.9)$ \\
\hline Others & $1(1.1)$ \\
\hline \multicolumn{2}{|l|}{ Laparoscopic surgery } \\
\hline Yes & $9(10.3)$ \\
\hline No & $78(89.7)$ \\
\hline \multicolumn{2}{|l|}{ Diversion at the initial operation } \\
\hline Yes & $60(69.0)$ \\
\hline No & $27(31.0)$ \\
\hline \multicolumn{2}{|l|}{ Permanent stoma } \\
\hline Yes & $42(48.3)$ \\
\hline No & $45(51.7)$ \\
\hline
\end{tabular}

Values are presented as $n(\%)$.

NA, not available; IPAA, ileal pouch-anal anastomosis.

\section{Chronological Changes}

To further analyze the changes over time, we divided the past 20 years into quarters, with 5 years for each period. We found that the enrolled number of surgeries increased chronologically from three during 1994-1999, five during 1999-2004, 32 during 2004-2009, to 35 during 2009-2014
(Table 1). To facilitate further analysis, we separated the study period into the periods before and after 2009 (Table 3 ). No patients received calcineurin inhibitors or anti-TNF- $\alpha$ agents before 2009. After 2009, two patients received calcineurin inhibitors and one patient received anti-TNF- $\alpha$ agents before surgery. There were also changes in surgical methods between the periods before and after 2009. Total or subtotal colectomy with rectal preservation and total abdominal proctocolectomy with IPAA were the two major surgical methods before 2009, while total or subtotal colectomy with rectal preservation and segmental colectomy were the two leading surgical methods after 2009. In addition, there were significantly more surgeries performed laparoscopically after 2009 .

\section{Analysis of the Factors Associated With Mortality}

The mortality rate was $8.1 \%$. All six non-survivors had extensive colitis at the time of diagnosis. The interval between diagnosis and surgery was $<1$ year in four patients $(66.7 \%)$. Before surgery, five patients received 5-ASA, two patients systemic steroids, and one patient azathioprine. The cause of death was sepsis in all cases. Four patients died within 30 days post-operatively. One patient died on the 40th day after surgery and the other died on the 61th day post-operatively. Among them, five patients received an emergency operation. Three patients received ileostomy, two patients received subtotal colectomy, and one patient received right hemicolectomy.

We tried to identify the possible risk factors for nonsurvivors who underwent surgery for UC (Table 4). In the analysis, pre-operative albumin level was significantly lower in the non-survival group than in the survival group $(2.6 \pm 0.3$ vs. $3.3 \pm 0.9 \mathrm{~g} / \mathrm{dL}, P=0.004)$ according to Student's $t$-test. Compared to elective surgery, emergency surgery significantly more associated with non-survival $(P=0.017)$. Furthermore, using the Kaplan-Meier method and log-rank test, patients with a pre-operative albumin level $>2.5 \mathrm{~g} / \mathrm{dL}$ were shown to have significantly better survival than patients with an albumin level $<2.5 \mathrm{~g} / \mathrm{dL}$ before surgery $(P=0.034)$ (Fig. 1$)$. Patients who underwent elective surgery had a significantly better survival rate than patients who underwent emergency surgery $(P=0.013)$ (Fig. 2).

\section{DISCUSSION}

Although most UC patients are treated and controlled effectively with a wide variety of medications, approximately 
Table 3. Chronological Changes in Surgical Methods Before and After 2009

\begin{tabular}{|c|c|c|c|}
\hline Item & Before 2009 & After 2009 & $P$-value \\
\hline Age & $46.6 \pm 12.7$ & $41.6 \pm 18.2$ & 0.180 \\
\hline BMI & $21.5 \pm 4.0$ & $20.6 \pm 3.8$ & 0.471 \\
\hline Sex & & & 0.128 \\
\hline Male & $23(57.5)$ & $26(74.3)$ & \\
\hline Female & $17(42.5)$ & $9(25.7)$ & \\
\hline Extent at diagnosis & & & $0.236^{\mathrm{a}}$ \\
\hline Proctitis & $3(7.5)$ & 0 & \\
\hline Left-side colitis & $7(17.5)$ & $8(23.5)$ & \\
\hline Extensive colitis & $30(75.0)$ & $26(76.5)$ & \\
\hline \multicolumn{4}{|l|}{ Medications before operation } \\
\hline 5-ASA or sulfasalazine & $28(70.0)$ & $25(71.4)$ & 0.770 \\
\hline Systemic steroid & $17(42.5)$ & $17(48.6)$ & 0.225 \\
\hline Immunomodulators & $1(2.5)$ & $1(2.8)$ & $0.587^{\mathrm{a}}$ \\
\hline Calcineurin inhibitors & 0 & $2(5.7)$ & $0.089^{\mathrm{a}}$ \\
\hline TNF antagonists & 0 & $1(2.8)$ & $0.455^{\mathrm{a}}$ \\
\hline Indication for operation & & & $0.932^{\mathrm{a}}$ \\
\hline Toxic megacolon & $3(8.3)$ & $2(8.0)$ & \\
\hline Toxic colitis & $4(11.1)$ & $3(12.0)$ & \\
\hline Perforation & $6(16.7)$ & $6(24.0)$ & \\
\hline Uncontrolled bleeding & $9(25.0)$ & $4(16.0)$ & \\
\hline Intractability & $7(19.4)$ & $3(12.0)$ & \\
\hline Stenosis & $2(5.6)$ & $2(8.0)$ & \\
\hline Dysplasia or adenocarcinoma & $3(8.3)$ & $4(16.0)$ & \\
\hline Adhesion ileus & $2(5.6)$ & $1(4.0)$ & \\
\hline Emergency or elective & & & 1.000 \\
\hline Emergency & $13(33.3)$ & $11(33.3)$ & \\
\hline Elective & $26(66.7)$ & $22(66.7)$ & \\
\hline Operation method & & & 0.058 \\
\hline Proctocolectomy with ileostomy & $1(2.7)$ & $2(5.7)$ & \\
\hline Total/subtotal colectomy with rectal preservation & $18(45.9)$ & $11(31.4)$ & \\
\hline Total abdominal proctocolectomy with IPAA & $13(32.4)$ & $5(14.3)$ & \\
\hline Segmental colectomy & $5(10.8)$ & $10(28.6)$ & \\
\hline Hartmann procedure & $2(5.4)$ & $1(2.9)$ & \\
\hline Diverting loop ileostomy & $1(2.7)$ & $5(14.3)$ & \\
\hline Abdominoperineal resection & 0 & $1(2.9)$ & \\
\hline Disease status after operation & & & $0.321^{\mathrm{a}}$ \\
\hline Active & $2(5.9)$ & $6(18.2)$ & \\
\hline Remission & $32(94.1)$ & $27(81.8)$ & \\
\hline Disease to operation & & & $0.330^{\mathrm{a}}$ \\
\hline$\leq 1 \mathrm{yr}$ & $24(60.0)$ & $14(41.2)$ & \\
\hline $1-5$ yrs & $6(15.0)$ & $6(17.6)$ & \\
\hline $6-10$ yrs & $5(12.5)$ & $5(14.7)$ & \\
\hline$\geq 10$ yrs & $5(12.5)$ & $9(26.5)$ & \\
\hline Laparoscopic surgery & & & $0.010^{\mathrm{a}}$ \\
\hline Yes & $1(2.5)$ & $8(22.9)$ & \\
\hline No & $39(97.5)$ & $27(77.1)$ & \\
\hline Diversion or not (initial operation) & & & 0.805 \\
\hline Yes & $28(70.0)$ & $23(65.7)$ & \\
\hline No & $12(30.0)$ & $12(34.3)$ & \\
\hline
\end{tabular}

Values are presented as mean \pm SD or $n(\%)$.

${ }^{a}$ Fisher's exact test.

5-ASA, 5-aminosalicylic acid; TNF, tumor necrosis factor; IPPA, lleal pouch-anal anastomosis. 
Table 4. Differences in the Characteristics of Survivors and Non-Survivors After Surgery for Ulcerative Colitis

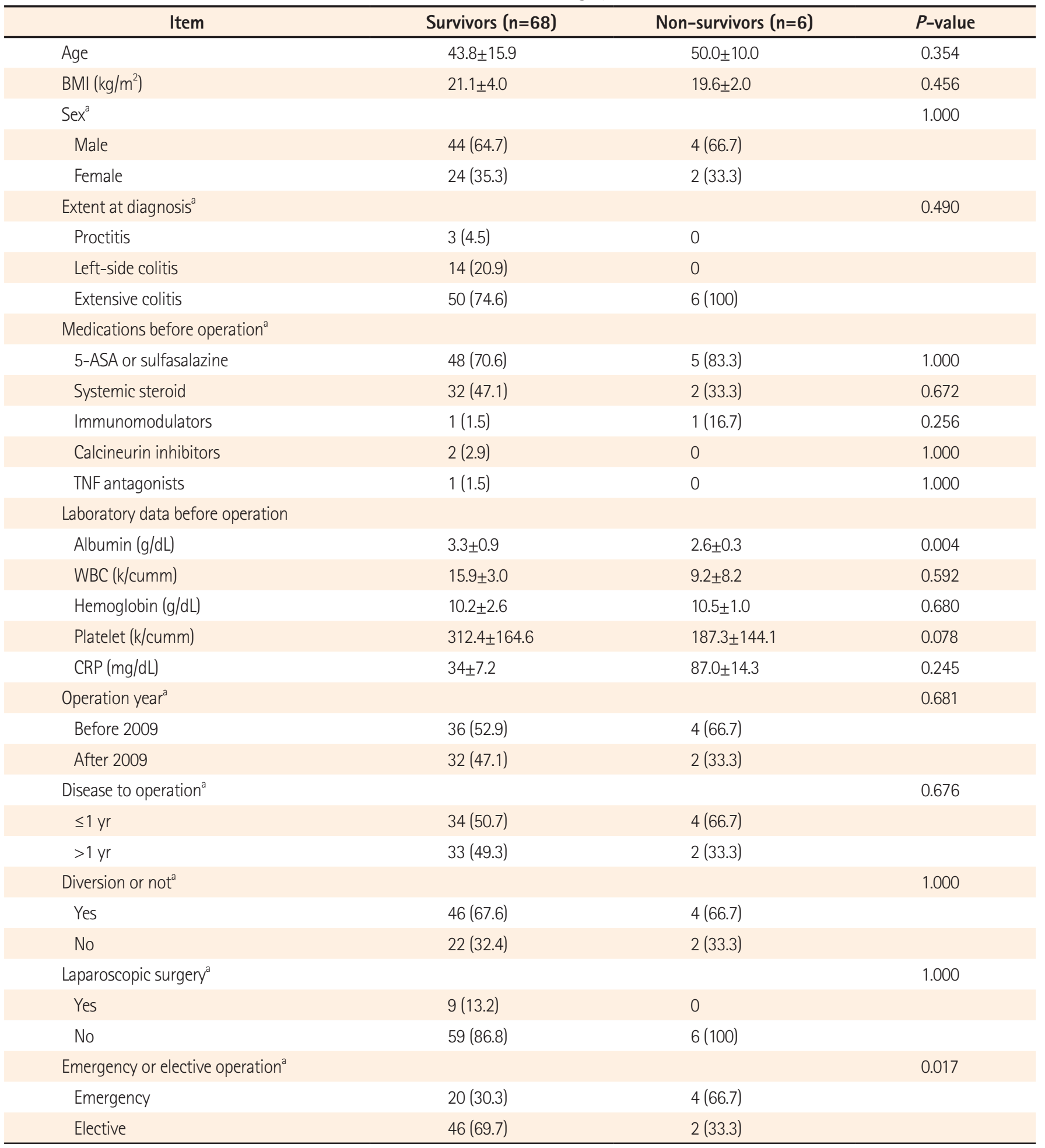

Values are presented as mean \pm SD or $n(\%)$.

aFisher's exact test.

5-ASA, 5-aminosalicylic acid; TNF, tumor necrosis factor; WBC, white blood cells. 


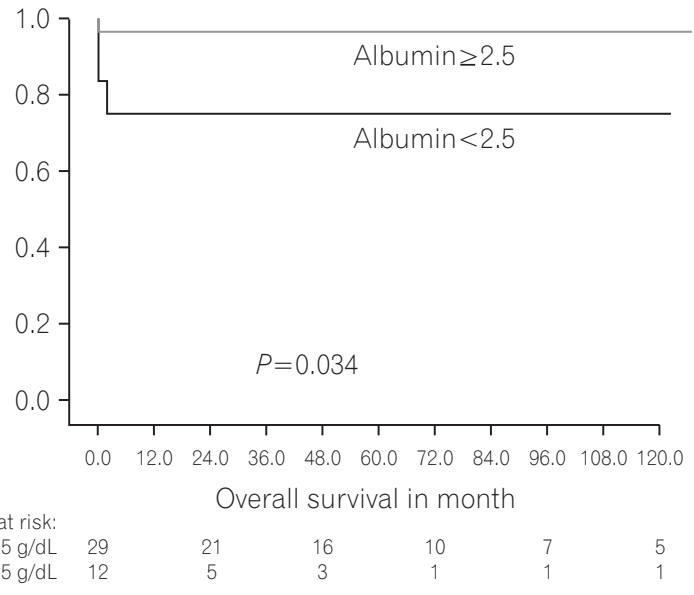

Fig. 1. The patient overall survival depends on albumin level. Patients with a pre-operative albumin level $\geq 2.5 \mathrm{~g} / \mathrm{dL}$ had a significant better survival rate than patients with an albumin level $<2.5 \mathrm{~g} / \mathrm{dL}$

$15 \%-45 \%$ of patients require or elect for surgery in Western countries. $^{32,33}$ In Asia, studies focusing on surgical management with long-term follow-up data for UC patients are scarce, and the results are conflicting. Jiang et al. ${ }^{12}$ reported that only $3 \%$ of patients required surgery in China. Hiwatashi et al. ${ }^{13}$ published a long-term follow-up study from 19731990, and found that 114 of 778 patients (14.7\%) received a colectomy in China. Results from 304 Korean UC patients between 1989 and 2005 demonstrated that the cumulative probability of colectomy was $2.0 \%$ after 1 year, $2.8 \%$ after 3 years, and $3.3 \%$ after $5-15$ years. ${ }^{14}$ Our results showed that there were only 87 colectomies in the study period of 20 years. In one of the hospitals (National Taiwan University Hospital), there were 742 admissions due to UC from 19912014. Among them, 14 patients received colectomy and the estimated colectomy rate was $1.9 \%$. The low colectomy rate in Taiwan added further evidence for the lower colectomy rate in Asia compared to that in Western countries. The possible reasons included milder clinical courses and the fact that Asian people are more reluctant to undergo colectomy. Koreans are thought to have a milder course than Westerners, as indicated by the lower rate of colectomy among Koreans. ${ }^{17}$ Currently, we keep both possibilities of treatment open for Taiwanese patients, as we have no direct evidence of a milder disease course. In addition, Taiwanese people cannot easily be persuaded to undergo colectomy.

Our results revealed that the overall post-operative mortality rate was $6 / 74(8.1 \%)$, and in all cases, the cause of death was sepsis during the first 2 months after surgery. The mortality rates were $17.4 \%$ and $4.3 \%$ for emergent and elective surgeries, respectively. The post-operative mortality rate has

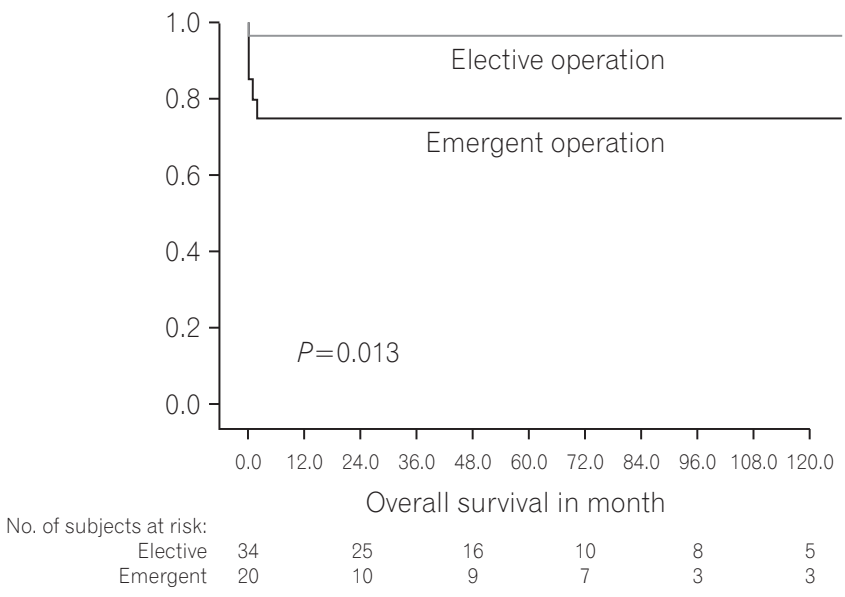

Fig. 2. The patient overall survival depends on elective or emergency surgery. Patients who underwent elective surgery had a significantly better survival rate than patients who underwent emergency surgery.

been reported as $2.4 \%-13.6 \%$ for emergent surgeries, ${ }^{25,34-36}$ and $0.6 \%-5.6 \%$ for elective surgeries. ${ }^{25,34-36}$ The reasons for the higher mortality rate in our study may be due to the higher proportion of emergent surgeries performed and poor general patient condition before surgery, which meant that $50 \%$ of the non-survivors could only receive diversion. There are some predictive variables for post-operative 30day mortality in UC patients, such as emergent versus elective surgery, ${ }^{25,36}$ age, ${ }^{26,36,37}$ male sex, ${ }^{37}$ Clostridium difficile infection, ${ }^{37}$ low volume or high volume of surgery for $\mathrm{UC}_{,}{ }^{26}$ and increased comorbidities. ${ }^{26}$ In addition to emergent surgery, we demonstrated that a lower pre-operative albumin level was a significant factor for post-operative mortality. Low albumin level might be related to poor nutrition as well as high inflammatory activity. Therefore, when aiming to decrease post-operative mortality rates, clinicians should optimize medical treatment to decrease inflammation and provide good nutritional support in order to minimize the probability of the patient requiring emergent surgery.

The three leading indications for surgical intervention in the current study were uncontrolled bleeding (16.1\%), perforation (13.8\%), and intractability (12.6\%). Although there was no significant change in the indications for surgery before and after 2009, we observed that dysplasia or adenocarcinoma increased up to two-fold after 2009 ( $16.0 \%$ vs. 8.3\%). The reasons for this may be the improved quality of equipment for the detection of dysplasia. ${ }^{38}$ Besides, a more aggressive usage of medication to control the inflammation associated with UC could reduce the need for emergent surgery. However, the role of medication to prevent carcinogenesis remains elusive. 
It has been reported that restorative proctocolectomy with IPAA, as described first by Parks and Nicholls in $1978^{39}$ and Utsunomiya in $1980,{ }^{40}$ is the standard of care for patients with UC who require surgery. ${ }^{32}$ Moreover, some studies have showed that subtotal colectomy is a safe surgical option for acute severe colitis. ${ }^{41}$ In our series, more patients received total or subtotal colectomy with rectal preservation than total abdominal proctocolectomy with IPAA (41.4\% vs. 25.3\%). Thirteen patients (32.4\%) in the cohort before 2009 and five patients (14.3\%) in the cohort after 2009 received total abdominal proctocolectomy with IPAA. Although large-scale studies have showed that good functional outcomes can be expected in most patients receiving total proctocolectomy with IPAA, ${ }^{32,42} 2.4 \%-15.5 \%$ patients still experience pouch failure, ${ }^{43,44}$ and approximately one-third of patients experience pouchitis. ${ }^{42}$ As Taiwan is a low-endemic area, it would not be possible to have a high surgical volume center for UC. In the study period, the number of patients at each center ranged from 5 to 24 . This may explain the low incidence of total proctocolectomy with IPAA in Taiwan. In addition, although most patients had their rectum preserved, 32 out of 40 patients (80\%) experienced remission. This may be another reason for the lower prevalence of total proctocolectomy with IPAA in Taiwan, especially after 2009.

Over the past decades, therapy for IBD has changed due to the widespread use of unosuppressive therapy (purine antimetabolites and methotrexate) and the introduction of anti-TNF therapy. ${ }^{9}$ The overall effectiveness of IMMs and anti-TNF agents in reducing the need for surgery in UC remains controversial. ${ }^{45-47}$ In this study, because very few UC patients received IMMs and/or calcineurin inhibitors and antiTNF agents, we could not draw any definitive conclusions from the data. So far, there is no evidence for the impact of medical therapy on surgery in UC patients.

There were some limitations to the current study. First, this was a retrospective multi-center study with a significant amount of missing data. Therefore, exact information on medications, disease activities, durations of hospitalization, and patient comorbidities and statuses was not available for analysis. Second, we had no population data for the UC patients during the study period. Many short segment colitis or proctitis patients were not properly registered. Therefore, it is difficult to elucidate whether the chronological increase in the number of surgeries was due to an increased risk for surgery in UC patients or the result of sampling bias.

In summary, our results demonstrate that in the past 20 years, the three leading indications for the surgical management of UC were uncontrolled bleeding, perforation, and intractability. More patients received laparoscopic surgery in the most recent 5 years (since 2009). In addition, lower albumin levels $(<2.5 \mathrm{~g} / \mathrm{dL})$ and emergent surgery were associated with mortality. Therefore, the optimal timing of elective surgery in people with poorly controlled UC is of paramount importance.

\section{REFERENCES}

1. Wilks S. Morbid appearances in the intestines of Miss Banks. Med Times Gazette 1859;2:264-265.

2. Loftus EV, Jr. Clinical epidemiology of inflammatory bowel disease: Incidence, prevalence, and environmental influences. Gastroenterology 2004;126:1504-1517.

3. Kornbluth A, Sachar DB; Practice Parameters Committee of the American College of Gastroenterology. Ulcerative colitis practice guidelines in adults: American College Of Gastroenterology, Practice Parameters Committee. Am J Gastroenterol 2010;105:501-523.

4. Sandborn WJ, Hanauer SB. Systematic review: the pharmacokinetic profiles of oral mesalazine formulations and mesalazine pro-drugs used in the management of ulcerative colitis. Aliment Pharmacol Ther 2003;17:29-42.

5. Desreumaux P, Ghosh S. Review article: mode of action and delivery of 5-aminosalicylic acid - new evidence. Aliment Pharmacol Ther 2006;24(Suppl 1):2-9.

6. Ho GT, Chiam P, Drummond H, Loane J, Arnott ID, Satsangi J. The efficacy of corticosteroid therapy in inflammatory bowel disease: analysis of a 5-year UK inception cohort. Aliment Pharmacol Ther 2006;24:319-330.

7. Dignass A, Lindsay JO, Sturm A, et al. Second European evidence-based consensus on the diagnosis and management of ulcerative colitis part 2: current management. J Crohns Colitis 2012;6:991-1030.

8. Cohen RD, Stein R, Hanauer SB. Intravenous cyclosporin in ulcerative colitis: a five-year experience. Am J Gastroenterol 1999;94:1587-1592.

9. Rutgeerts P, Sandborn WJ, Feagan BG, et al. Infliximab for induction and maintenance therapy for ulcerative colitis. N Engl J Med 2005;353:2462-2476.

10. Bach SP, Mortensen NJ. Ileal pouch surgery for ulcerative colitis. World J Gastroenterol 2007;13:3288-3300.

11. Bernstein CN, Ng SC, Lakatos PL, et al. A review of mortality and surgery in ulcerative colitis: milestones of the seriousness of the disease. Inflamm Bowel Dis 2013;19:2001-2010.

12. Jiang L, Xia B, Li J, et al. Retrospective survey of 452 patients with inflammatory bowel disease in Wuhan city, central China. Inflamm Bowel Dis 2006;12:212-217. 
13. Hiwatashi N, Yao T, Watanabe H, et al. Long-term follow-up study of ulcerative colitis in Japan. J Gastroenterol 1995;30(Suppl 8):13-16.

14. Park SH, Kim YM, Yang SK, et al. Clinical features and natural history of ulcerative colitis in Korea. Inflamm Bowel Dis 2007;13:278-283.

15. Wang Y, Ouyang Q; APDW 2004 Chinese IBD working group. Ulcerative colitis in China: retrospective analysis of 3100 hospitalized patients. J Gastroenterol Hepatol 2007;22:1450-1455.

16. Lee HS, Park SH, Yang SK, et al. Long-term prognosis of ulcerative colitis and its temporal change between 1977 and 2013: a hospital-based cohort study from Korea. J Crohns Colitis 2015;9:147-155

17. Lee HS, Yang SK, Soh JS, et al. Short- and long-term outcomes of acute severe ulcerative colitis in Korea: the 1999-2005 cohort. Inflamm Bowel Dis 2015;21:1825-1831.

18. Pal S, Sahni P, Pande GK, Acharya SK, Chattopadhyay TK. Outcome following emergency surgery for refractory severe ulcerative colitis in a tertiary care centre in India. BMC Gastroenterol 2005;5:39.

19. Sands BE. Fulminant colitis. J Gastrointest Surg 2008;12:21572159.

20. Meagher AP, Farouk R, Dozois RR, Kelly KA, Pemberton JH. J ileal pouch-anal anastomosis for chronic ulcerative colitis: complications and long-term outcome in 1310 patients. Br J Surg 1998;85:800-803.

21. Michelassi F, Lee J, Rubin M, et al. Long-term functional results after ileal pouch anal restorative proctocolectomy for ulcerative colitis: a prospective observational study. Ann Surg 2003;238:433-441.

22. Carter FM, McLeod RS, Cohen Z. Subtotal colectomy for ulcerative colitis: complications related to the rectal remnant. Dis Colon Rectum 1991;34:1005-1009.

23. Hyman NH, Cataldo P, Osler T. Urgent subtotal colectomy for severe inflammatory bowel disease. Dis Colon Rectum 2005;48:70-73.

24. Ikeuchi H, Uchino M, Matsuoka H, et al. Surgery for ulcerative colitis in 1,000 patients. Int J Colorectal Dis 2010;25:959-965.

25. Tøttrup A, Erichsen R, Sværke C, Laurberg S, Srensen HT. Thirty-day mortality after elective and emergency total colectomy in Danish patients with inflammatory bowel disease: a population-based nationwide cohort study. BMJ Open 2012;2:e000823. doi: 10.1136/bmjopen-2012-000823.

26. Kaplan GG, McCarthy EP, Ayanian JZ, Korzenik J, Hodin R, Sands BE. Impact of hospital volume on postoperative morbidity and mortality following a colectomy for ulcerative colitis. Gastroenterology 2008;134:680-687.
27. Ooi CJ, Fock KM, Makharia GK, et al. The Asia-Pacific consensus on ulcerative colitis. J Gastroenterol Hepatol 2010;25:453468.

28. Silverberg MS, Satsangi J, Ahmad T, et al. Toward an integrated clinical, molecular and serological classification of inflammatory bowel disease: report of a Working Party of the 2005 Montreal World Congress of Gastroenterology. Can J Gastroenterol 2005;19(Suppl A):5A-36A

29. Jones JH, Chapman M. Definition of megacolon in colitis. Gut 1969;10:562-564.

30. Truelove SC, Witts LJ. Cortisone in ulcerative colitis; final report on a therapeutic trial. Br Med J 1955;2:1041-1048.

31. Dignass A, Eliakim R, Magro F, et al. Second European evidence-based consensus on the diagnosis and management of ulcerative colitis part 1: definitions and diagnosis. J Crohns Colitis 2012;6:965-990.

32. Ross H, Steele SR, Varma M, et al. Practice parameters for the surgical treatment of ulcerative colitis. Dis Colon Rectum 2014;57:5-22.

33. Mowat C, Cole A, Windsor A, et al. Guidelines for the management of inflammatory bowel disease in adults. Gut 2011;60:571607.

34. Roberts SE, Williams JG, Yeates D, Goldacre MJ. Mortality in patients with and without colectomy admitted to hospital for ulcerative colitis and Crohn's disease: record linkage studies. BMJ 2007;335:1033. doi: http://dx.doi.org/10.1136/ bmj.39345.714039.55.

35. Nicholls RJ, Clark DN, Kelso L, et al. Nationwide linkage analysis in Scotland implicates age as the critical overall determinant of mortality in ulcerative colitis. Aliment Pharmacol Ther 2010;31:1310-1321.

36. de Silva S, Ma C, Proulx MC, et al. Postoperative complications and mortality following colectomy for ulcerative colitis. Clin Gastroenterol Hepatol 2011;9:972-980.

37. Nguyen GC, Laveist TA, Gearhart S, Bayless TM, Brant SR. Racial and geographic variations in colectomy rates among hospitalized ulcerative colitis patients. Clin Gastroenterol Hepatol 2006;4:1507-1513.

38. Deepak P, Hanson GJ, Fletcher JG, et al. Incremental diagnostic yield of chromoendoscopy and outcomes in inflammatory bowel disease patients with a history of colorectal dysplasia on white-light endoscopy. Gastrointest Endosc 2016;83:1005-1012.

39. Parks AG, Nicholls RJ. Proctocolectomy without ileostomy for ulcerative colitis. Br Med J 1978;2:85-88.

40. Utsunomiya J, Iwama T, Imajo M, et al. Total colectomy, mucosal proctectomy, and ileoanal anastomosis. Dis Colon Rectum 1980;23:459-466. 
41. Alves A, Panis Y, Bouhnik Y, Maylin V, Lavergne-Slove A, Valleur P. Subtotal colectomy for severe acute colitis: a 20-year experience of a tertiary care center with an aggressive and early surgical policy. J Am Coll Surg 2003;197:379-385.

42. Fazio VW, Kiran RP, Remzi FH, et al. Ileal pouch anal anastomosis: analysis of outcome and quality of life in 3707 patients. Ann Surg 2013;257:679-685.

43. Dayton MT, Larsen KR, Christiansen DD. Similar functional results and complications after ileal pouch-anal anastomosis in patients with indeterminate vs ulcerative colitis. Arch Surg 2002;137:690-694.

44. Leowardi C, Hinz U, Tariverdian M, et al. Long-term outcome 10 years or more after restorative proctocolectomy and ileal pouch-anal anastomosis in patients with ulcerative colitis. Langenbecks Arch Surg 2010;395:49-56.
45. Filippi J, Allen PB, Hébuterne X, Peyrin-Biroulet L. Does antiTNF therapy reduce the requirement for surgery in ulcerative colitis? A systematic review. Curr Drug Targets 2011;12:14401447.

46. Aratari A, Papi C, Clemente V, et al. Colectomy rate in acute severe ulcerative colitis in the infliximab era. Dig Liver Dis 2008;40:821-826.

47. Moore SE, McGrail KM, Peterson S, et al. Infliximab in ulcerative colitis: the impact of preoperative treatment on rates of colectomy and prescribing practices in the province of British Columbia, Canada. Dis Colon Rectum 2014;57:83-90. 